\title{
A study on the cutaneous manifestations of an internal malignancy in a tertiary care center in North India
}

\author{
Neerja Puri, Sukhmani Kaur Brar, B. K. Brar \\ Department of Dermatology, G G S Medical College, Faridkot and Fortis Clinic, Mohali, India \\ Corresponding author: Neerja Puri, MD, E-mail: neerjaashu@rediffmail.com
}

\begin{abstract}
Introduction: Cutaneous metastases may precede a malignancy and, in other cases, herald the recurrence of a malignancy after surgery. Aim: To determine the significance of cutaneous manifestations in patients with an internal malignancy and to observe the various types of carcinomas in patients attending a dermatology OPD. Methods: This was a prospective hospital-based study undertaken to observe the cutaneous features in a dermatology OPD in patients coming from the oncology department of a medical college. Results: The commonest malignancy in males was a lung carcinoma, observed in $5.50 \%$ of the patients, followed by a prostate carcinoma, observed in $4.58 \%$ of the patients, an esophagus carcinoma, observed in $4.12 \%$ of the patients, and a penis carcinoma, observed in $2.29 \%$ of the patients. Specific cutaneous manifestations included cutaneous metastatic infiltrates, observed in $5.04 \%$ of the patients, and carcinoma erysipeloides, observed in $1.37 \%$ of the patients. Discussion: Skin metastases may herald the recurrence of a malignancy after treatment and usually indicate a poor prognosis.
\end{abstract}

Key words: Malignancy; Infiltrate; Cutaneous; Metastasis; Breast

\section{INTRODUCTION}

Internal malignancies involve various skin changes, among which some are related to the malignancy, such as malignant cutaneous infiltrates, some are treatment-related, mainly due to the toxic effect of the drugs taken, and some are non-specific [1]. Various internal malignancies give rise to cutaneous changes due to their immunological, metabolic, and metastatic consequences. The single most basic biologic process that characterizes a malignant tumor is the ability to produce secondary deposits (metastases) in distant sites. Generalized pruritis is one of the common cutaneous manifestations of a cutaneous metastasis. [2] The skin is an infrequent site for metastasis and was listed by one study as low as the eighteenth of the most common sites [3]. Cutaneous metastases may appear at any age. Considering, however, the increased incidence of malignant disease later in life, most cutaneous metastases occur during or after the fifth decade of life [4].

Cutaneous metastases are relatively uncommon but it is important to consider them. In some cases, they may precede a malignancy. Contiguous metastases are the most common in carcinoma of the breast and oral cavity and often herald the recurrence of a malignancy after surgery [1]. The trunk and the scalp are favored sites for distant metastases. The mortality rate is usually high with cutaneous metastases, although early recognition gives some chance of survival, especially in patients that present themselves with cutaneous metastases [5]. Cutaneous metastasis from an internal malignancy is relatively uncommon, with the incidence rate ranging from $0.7 \%$ to $10.4 \%$ as reported in various case series [6]. These metastatic deposits indicate a higher stage of malignant disease and, as in any other metastatic tumor deposits in a patient under treatment, signify a

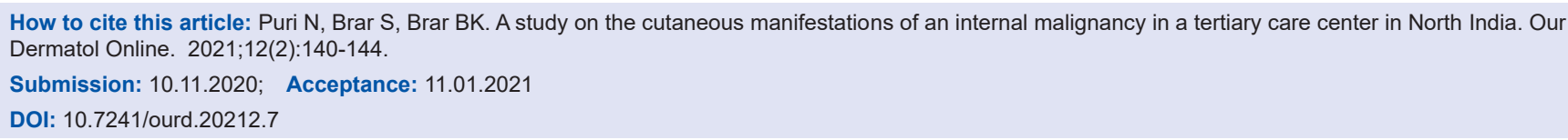


lack of response of the malignancy to treatment. The common sites of skin metastasis from a lung cancer are the head, neck, chest, and abdomen [7]. As skin metastases may be suspected and detected earlier compared to metastases in other organs, the clinician should be cognizant of the various visual aspects of such lesions, and the pathologist should be aware of the various patterns of metastatic deposits in the skin. A biopsy evaluation of these deposits often yields clues as to the probable site of the primary tumor, based on the histological appearance of the deposits.

\section{Aim}

The study was aimed at determining the significance of cutaneous manifestations in patients with an internal malignancy and to observe the various types of carcinomas in patients attending a dermatology OPD.

\section{MATERIALS AND METHODS}

A prospective hospital-based study was undertaken in a dermatology OPD to observe the cutaneous features in patients coming from the oncology department of a medical college and lasted for a period of two years from April 2018 through April 2020. Detailed clinical and cutaneous examinations were performed for all patients. Relevant investigations were performed as the need arose. Specific investigations such as skin biopsies were performed for patients with specific features, such as cutaneous infiltrates. The relevant clinical data, including the duration and type of the malignancy and the cutaneous features, were recorded.

\section{RESULTS}

The data was collected and the results were analyzed. As for the age distribution of the patients, the highest number of patients was between 40-60 years old (46.78\%), followed by $44.03 \%$ of the patients between 61-80 years old and $8.25 \%$ of the patients between $21-40$ years old. There were only $0.91 \%$ of patients below the age of 20 years. The study comprised 138 males and 80 females and the male-to-female ratio was 1.7 to 1 .

\section{DISCUSSION}

The age distribution (Table 1) in our study was somehow different from that by Puri et al. in which most (32.3\%) patients were in the age group 60-69 years
[8]. Only $0.8 \%$ of the patients were aged less than 10 years, and $2.6 \%$ were of age 80 years or older. Among the two patients below the age of 20 years, one was a six-year-old child with Wilms' tumor. The sex ratio in our study was different from a study by Hassan et al., in which 139 (55.6\%) patients were males and 111 $(44.4 \%)$ patients were females [9].

In our study, the most common malignancy (Table 2) in females was carcinoma of the breast, which was observed in $23.38 \%$ of the patients, followed by carcinoma of the cervix, observed in $9.17 \%$ of the patients, carcinoma of the ovary, observed in $4.12 \%$ of the patients, carcinoma of the endometrium, observed in $3.21 \%$ of the patients, and carcinoma of the vulva, observed in $0.45 \%$ of the patients. The most common malignancy in males was carcinoma of the lung, observed in $5.50 \%$ of the patients, followed by carcinoma of the prostate, observed in $4.58 \%$ of the patients, carcinoma of the esophagus, observed in $4.12 \%$ of the patients, and carcinoma of the penis, observed in $2.29 \%$ of the patients. This is in contrast to findings by Wani et al., which determined the esophagus and the gastrointestinal junction, followed by the lung and stomach, as the leading causes of malignancies [10]. Other malignancies observed both in males and females were leukemias, in $9.17 \%$ of the patients, lymphomas, in $8.71 \%$ of the patients, carcinoma of the tongue, in $5.04 \%$ of the patients, carcinoma of the larynx, in $3.66 \%$ of the patients, carcinoma of the colon, in $2.29 \%$ of the patients, carcinoma of the stomach, in $1.37 \%$ patients, carcinoma of the bladder, in $2.29 \%$ of the patients, carcinoma of the rectum, in $1.83 \%$ of the patients, carcinoma of the tonsil, in $1.37 \%$ of the patients, as well as carcinoma of the pancreas, hepatocellular carcinoma, carcinoma of the thyroid, brain tumor, renal cell carcinoma, and metastatic carcinomas, each in $0.91 \%$ of the patients. Wilms' tumor and nasopharyngeal carcinoma were observed each in $0.45 \%$ of the patients. $2.75 \%$ of the patients had a metastatic carcinoma with an unknown primary disease (Table 3). In our study, the most common cutaneous manifestation was generalized pruritis, observed in $17.88 \%$ of the patients, followed by acquired ichthyosis, observed in $11.46 \%$ of the patients, and herpes zoster (Fig. 1), observed in $12.38 \%$ of the patients. Other cutaneous features observed were pyodermas in $9.63 \%$ of the patients, dermatophytosis in $6.42 \%$ of the patients, candidal intertrigo and radiation dermatitis each in $4.12 \%$ of the patients, oral ulcers in $2.75 \%$ of the patients; scabies, eczemas, varicella zoster, and erythema multiforme each in $2.29 \%$ of the 
patients; erythroderma and maculopapular drug rash each in $1.83 \%$ of the patients; urticaria, irritant contact dermatitis, seborrheic dermatitis, and paronychia each in $1.37 \%$ of the patients; nail pigmentation (Fig. 2), genital warts (Fig. 3), and photodermatitis each in $0.91 \%$ of the patients; geographic tongue, pseudoporphyria, papular urticaria, pediculosis, lupus erythematosus, genital molluscum contagiosum, SJS/TEN, and lichenoid drug eruption each in $0.45 \%$ of the patients. Specific skin manifestations included cutaneous metastatic infiltrates (Fig. 4) in $5.04 \%$ of the patients and carcinoma erysipeloides in $1.37 \%$ of the patients. In our study, vincristine caused bluish nail pigmentation, and generalized pruritus was the most common in patients with leukemia, lymphoma, hepatocellular carcinoma, and carcinoma of the stomach. Malignancies associated with herpes zoster were carcinoma of the breast, carcinoma of the cervix, carcinoma of the prostate, and carcinoma of the esophagus.

A cutaneous metastasis from an internal malignancy indicates a late stage of the disease. The skin is the

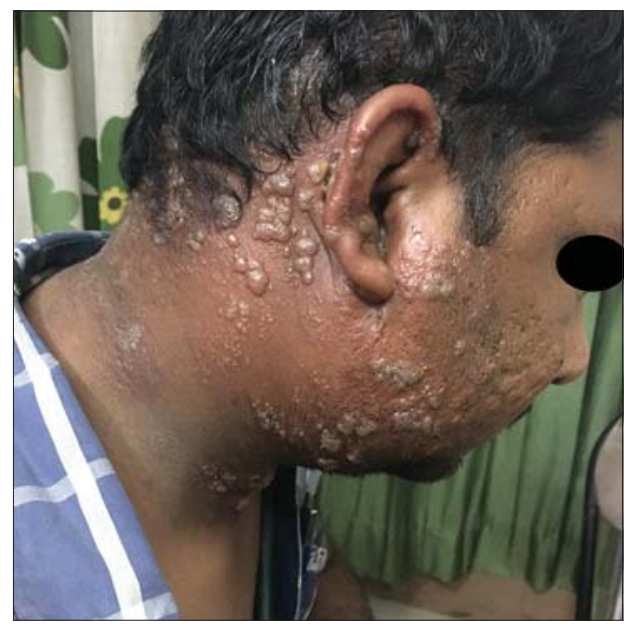

Figure 1: Herpes zoster in a 45-year-old male with carcinoma of the esophagus.

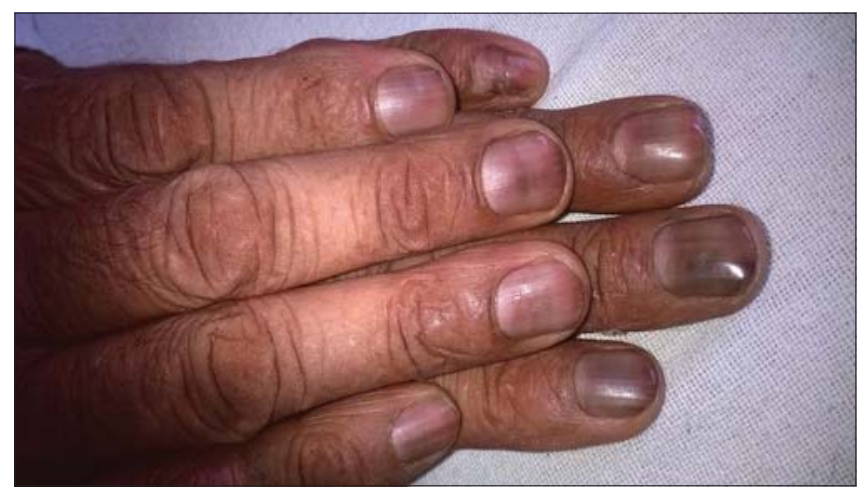

Figure 2: Nail pigmentation in a 48-year-old male secondary to vincristine. eighteenth most common site for cutaneous infiltrates, which is rare. Some of the internal malignancies, such as carcinoma of the breast, have a tendency to produce cutaneous infiltrates. The incidence of a cutaneous metastasis in our study was $5.04 \%$. Cutaneous infiltrates are mainly multiple. A cutaneous metastasis usually arises from carcinoma of the colon and lungs in males and from the colon, ovary, and breast in females. In our study, cutaneous infiltrates were the most common in the chest wall, followed by the abdomen, the face, and the extremities.

The skin often mirrors changes in the internal milieu, and skin metastases may herald the recurrence of a malignancy after treatment. A cutaneous metastasis may appear at any age, but most cutaneous metastases occur during or after the age of 55 years. The interval between the onset of the symptoms of the primary malignancy and the onset of the cutaneous metastasis

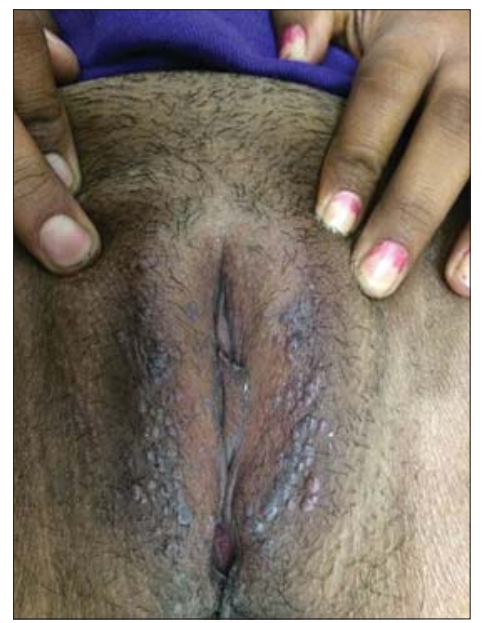

Figure 3: Genital warts in a 46-year-old female with carcinoma of the ovary.

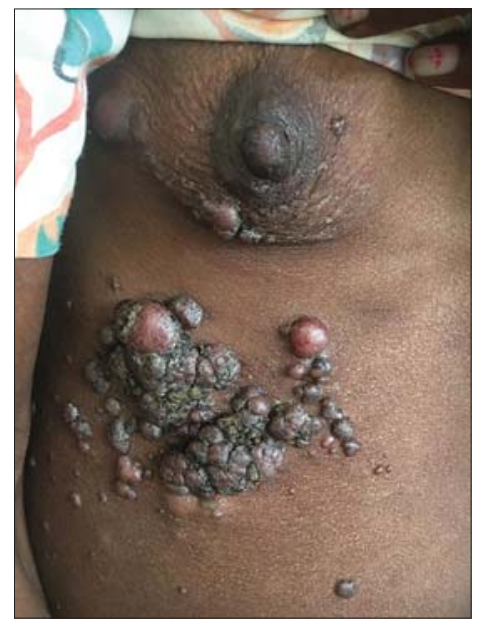

Figure 4: Nodular infiltrates in a 67-year-old female with carcinoma of the breast. 
Table 1: Age distribution among the patients

\begin{tabular}{cccc}
\hline & Age distribution (years) & No. of patients & Percentage \\
\hline 1 & $0-20$ & 2 & 0.91 \\
2 & $21-40$ & 18 & 8.25 \\
3 & $41-60$ & 102 & 46.78 \\
5 & $61-80$ & 96 & 44.03 \\
& Total & 218 & 100 \\
\hline
\end{tabular}

\begin{tabular}{|c|c|c|c|}
\hline & Type of malignancy & $\begin{array}{l}\text { No. of } \\
\text { patients }\end{array}$ & Percentage \\
\hline 1 & Carcinoma of the breast & 51 & 23.38 \\
\hline 2 & Carcinoma of the cervix & 20 & 9.17 \\
\hline 3 & Lymphoma & 19 & 8.71 \\
\hline 4 & Leukemia & 20 & 9.17 \\
\hline 5 & Carcinoma of the bladder & 5 & 2.29 \\
\hline 6 & Carcinoma of the penis & 5 & 2.29 \\
\hline 7 & Carcinoma of the larynx & 8 & 3.66 \\
\hline 8 & Carcinoma of the colon & 5 & 2.29 \\
\hline 9 & Carcinoma of the stomach & 3 & 1.37 \\
\hline 10 & Carcinoma of the prostate & 10 & 4.58 \\
\hline 11 & Carcinoma of the lung & 12 & 5.50 \\
\hline 12 & Carcinoma of the endometrium & 7 & 3.21 \\
\hline 13 & Carcinoma of the ovary & 9 & 4.12 \\
\hline 14 & Carcinoma of the rectum & 4 & 1.83 \\
\hline 15 & Carcinoma of the pancreas & 2 & 0.91 \\
\hline 16 & Carcinoma of the tongue & 7 & 5.04 \\
\hline 17 & Carcinoma of the tonsil & 3 & 1.37 \\
\hline 18 & Carcinoma of the nasopharynx & 1 & 0.45 \\
\hline 19 & Hepatocellular carcinoma & 2 & 0.91 \\
\hline 20 & Carcinoma of the ulva & 1 & 0.45 \\
\hline 21 & Wilms' tumor / renal cell carcinoma & 3 & 1.37 \\
\hline 22 & Carcinoma of the thyroid & 2 & 0.91 \\
\hline 23 & Carcinoma of the esophagus & 9 & 4.12 \\
\hline 24 & Metastatic carcinoma & 2 & 0.91 \\
\hline 25 & $\begin{array}{l}\text { Carcinoma with an unknown primary } \\
\text { disease }\end{array}$ & 6 & 2.75 \\
\hline \multirow[t]{2}{*}{26} & Brain tumor & 2 & 0.91 \\
\hline & Total & 218 & 100 \\
\hline
\end{tabular}

ranged from three months to six years. The shortest interval was three months in carcinoma of the lungs and the longest was six years in carcinoma of the breast.

The common malignancies that give rise to cutaneous metastases are carcinoma of the lung and colon in males and carcinoma of the colon and ovary in females. The incidence of cutaneous metastasis was the highest in the age group of 51 years and above $(52 \%)$. In our study, the chest (Fig. 5) was the most common site for a cutaneous metastasis, followed by the abdomen. Metastasis to the skin gives a poor chance of survival and a hopeless outcome.

Cutaneous manifestations still prove to be an enigma in the diagnosis of dermatological disorders and internal malignancies. Cutaneous manifestations should not be neglected and must be recognized by the physician in
Table 3: Cutaneous manifestations among the patients

\begin{tabular}{|c|c|c|c|}
\hline & Cutaneous manifestation & No. of patients & Percentage \\
\hline 1 & Generalized pruritis & 39 & 17.88 \\
\hline 2 & Scabies & 25 & 11.46 \\
\hline 3 & Tinea & 14 & 6.42 \\
\hline 4 & Pyodermas & 21 & 9.63 \\
\hline 5 & Herpes zoster & 27 & 12.38 \\
\hline 6 & Varicella zoster & 5 & 2.29 \\
\hline 7 & Nail pigmentation & 2 & 0.91 \\
\hline 8 & Urticaria & 3 & 1.37 \\
\hline 9 & Geographic tongue & 1 & 0.45 \\
\hline 10 & Radiation dermatitis & 9 & 4.12 \\
\hline 11 & Pseudoporphyria & 1 & 0.45 \\
\hline 12 & Cutaneous metastatic infiltrates & 11 & 5.04 \\
\hline 13 & Scabies & 5 & 2.29 \\
\hline 14 & Papular urticaria & 1 & 0.45 \\
\hline 15 & Erythroderma & 4 & 1.83 \\
\hline 16 & Carcinoma erysipeloides & 3 & 1.37 \\
\hline 17 & Lupus erythematosus & 1 & 0.45 \\
\hline 18 & Pediculosis & 1 & 0.45 \\
\hline 19 & Seborrheic dermatitis & 3 & 1.37 \\
\hline 20 & Irritant contact dermatitis & 3 & 1.37 \\
\hline 21 & Candidal intertrigo & 9 & 4.12 \\
\hline 22 & Erythema multiforme & 5 & 2.29 \\
\hline 23 & Photodermatitis & 2 & 0.91 \\
\hline 24 & Genital molluscum contagiosum & 1 & 0.45 \\
\hline 25 & Paronychia & 3 & 1.37 \\
\hline 26 & SJS/TEN & 1 & 0.45 \\
\hline 27 & Lichenoid drug eruption & 1 & 0.45 \\
\hline 28 & Maculopapular drug rash & 4 & 1.83 \\
\hline 29 & Eczemas & 5 & 2.29 \\
\hline 30 & Oral ulcers & 6 & 2.75 \\
\hline \multirow[t]{2}{*}{31} & Genital warts & 2 & 0.91 \\
\hline & Totel & 218 & 100 \\
\hline
\end{tabular}

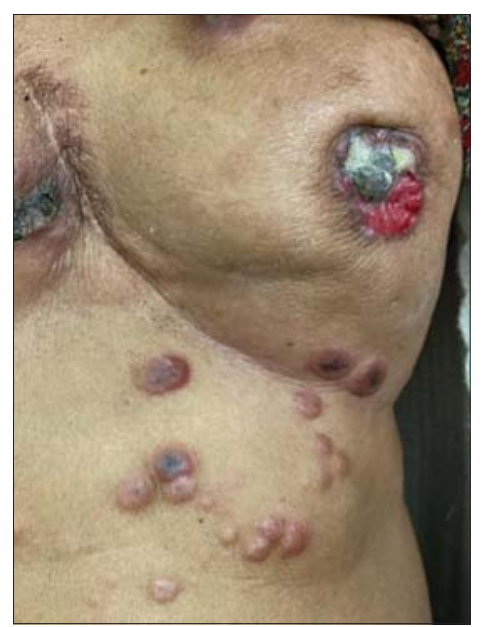

Figure 5: Cutaneous infiltrates on the chest wall in a 74-year-old female.

time. Some life-threatening hypersensitivity reactions, such as Steven-Johnson syndrome, must be treated in an intensive care unit, as in treating a patient with burns to counter an electrolyte loss and restore the body to a state of equilibrium. 


\section{CONCLUSION}

Cutaneous metastases indicating signs of recurrence as well as widespread metastases give poor prognosis and reduce the length of the survival period. A systemic response to any particular chemotherapeutic agent may be assessed by a visible regression of the skin metastasis. It is important to recognize a cutaneous metastasis in time as it may precede an internal visceral metastasis, especially because early recognition helps in prolonging the survival of the patient. The morphological features of the primary tumor are often reflected in the cutaneous metastatic deposits, and attempts to suggest a possible primary site during a skin biopsy evaluation help the clinician in narrowing down the primary tumor possibilities and in initiating specific radio-imaging and other relevant investigations for the patient's management as early as possible.

\section{Statement of Human and Animal Rights}

All the procedures followed were in accordance with the ethical standards of the responsible committee on human experimentation (institutional and national) and with the 2008 revision of the Declaration of Helsinki of 1975.

\section{Statement of Informed Consent}

Informed consent for participation in this study was obtained from all patients.

\section{REFERENCES}

1. Ayyamperumal A, Tharini GK, Ravindran V, Parveen B. Cutaneous manifestations of internal malignancy. Indian J Dermatol. 2012;57:260-4.

2. Fett N, Haynes K, Propert KJ, Margolis DJ. 5-year malignancy incidence in chronic pruritus patients: A population-based cohort study aimed at limiting unnecessary screening practices. J Am Acad Dermatol. 2014;70:651-8.

3. Wright TS. Cutaneous manifestations of malignancy. Curr Opin Pediatr. 2011;23:407-11.

4. Badwe RA, Dikshit R, Laversanne M, Bray F. Cancer incidence trends in India. Jpn J Clin Oncol. 2014;44:401-7.

5. Wong CY, Helm MA, Kalb RE, Helm TN, Zeitouni NC. The presentation, pathology, and current management strategies of cutaneous metastasis. N Am J Med Sci. 2013;5:499-504.

6. Sittart JA, Senise M. Cutaneous metastasis from internal carcinomas: A review of 45 years. An Bras Dermatol. 2013;88:541-4.

7. Owen CE. Cutaneous manifestations of lung cancer. Semin Oncol. 2016;43:366-9.

8. S Puri, M Ashat, A Pandey, NK Goel, A Singh, V Kaushal. Sociodemographic characteristics of cancer patients: Hospital based cancer registry in a tertiary care hospital of India. Indian J Cancer. 2014:51;1-4.

9. Hassan I, Zeerak S, Kuchay S, Bashir S, Bhat YJ, Mubashir S, et al. Cutaneous changes in internal malignancy: Study from a tertiary care center. Indian J Dermatol Venereol Leprol. 2017;83:276.

10. MA Wani, FA Jan, NA Khan, KK Pandita, R Khurshid, SH Khan. Cancer trends in Kashmir; common types, site incidence and demographic profiles: National Cancer Registry 2000-2012. Indian J Cancer. 2014:51;133-7.

Copyright by Neerja Puri, et al. This is an open access article distributed under the terms of the Creative Commons Attribution License, which permits unrestricted use, distribution, and reproduction in any medium, provided the original author and source are credited.

Source of Support: Nil, Conflict of Interest: None declared. 